\title{
Application of tetratozilat meso-tetrakis (4-methylpyridil)porphyrin as effective sensor for metal cations in plasma-solution systems
}

\author{
Artur Vashurin $^{1^{*}}$, Svetlana Pukhovskaya ${ }^{1}$, Ludmila Kuzmicheva $^{2}$, Yuliya Titova ${ }^{2}$ \\ Oleg Golubchikov ${ }^{3}$ \\ ${ }^{1}$ Department of Inorganic Chemistry, Ivanovo State University of Chemistry and Technology, Ivanovo, Russia; \\ *Corresponding Author: asv87@mail.ru \\ ${ }^{2}$ G. A. Krestov Institute of Solution Chemistry, Russian Academy of Sciences, Ivanovo, Russia \\ ${ }^{3}$ Department of Organic Chemistry, Ivanovo State University of Chemistry and Technology, Ivanovo, Russia
}

Received 29 May 2012; revised 28 June 2012; accepted 11 July 2012

\begin{abstract}
Synthetic porphyrins have, in the last years, gained increasing interest in analytical chemistry as unique reagents for the detection of metal ions. The porphyrin is a high sensitive chromogenic reagent. Porphyrins and their metal complexes generally exhibit characteristic sharp and intensive absorption bands in visible region. The region from 400 to $500 \mathrm{~nm}$, which is called the Soret band, shows the most intensive absorption, and molar absorptivities about $10^{5}$ are often found. Soret band (400 - $500 \mathrm{~nm}$ ) shows the most intensive absorption of these compounds, molar absorptivities often being about $10^{5}$. The Soret band is widely used for spectrophotometric detection of metalloporphyrins. From the perspective of analytical chemistry, the porphyrin ligand has turned out to be very versatile, and almost all metals have been combined with porphyrin. From this point of view several porphyrins become useful as the spectrophotometric reagents for the determination of metal ions.
\end{abstract}

Keywords: Porphyrin; Metallocomplex; Gas Discharge Plasma; Plasma-Solution System

\section{INTRODUCTION}

There is sufficient interest towards plasmachemical processes arising at the action of gas discharge plasma at water and electrolyte solutions. It is due to prospects of plasma-solution system applications for water purification and sterilization [1-4], surface modification of synthetic and native polymer materials [5-7], synthesis of nanomaterials $[8,9]$.
The simplest type of plasma-solution system is that with atmospheric pressure glow discharge with electrolyte cathode (Figure 1).

Glow discharge ignition between metal electrode and electrolite surface initiate redox reactions in the solution. The main role in these processes belongs to active particles formed in solution surface layer under the action of ion bombardment $\left(\mathrm{H}^{\prime}, \mathrm{HO}, e_{\text {solv }}\right)[10]$. This layer is very thin (tens of $\mathrm{nm}$ ), but despite it primary active species have time to react within it. Redox processes in the rest solution volume go with the participation of secondary active species, formed under the interaction of primary active agents with solvent molecules and with each other. Main of them is hydrogen peroxide [10,11].

$\mathrm{H}_{2} \mathrm{O}_{2}$ amount in the system accumulating under glow discharge action is in the dependence of various factors with cathode material among them. There is cathode partial destruction in the course of discharge ignition, $\mathrm{H}_{2} \mathrm{O}_{2}$ decomposition being catalyzed by metal ions $[12,13]$. In order to organize effective plasma-solution system, these processes must be taken into account, so as cation concentrations in the solution.

The aim of present work was the investigation of the kinetics of metal ion accumulation in electrolyte solution under the action of atmospheric pressure glow discharge

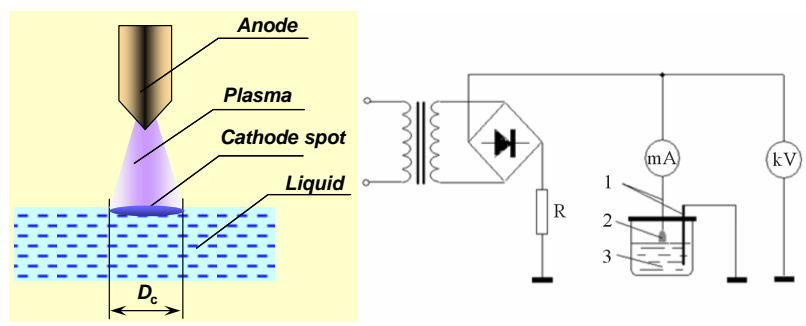

Figure 1. The scheme of atmospheric pressure glow discharge with electrolyte cathode. $D_{c}$ - cathode spot diameter. 1 - electrodes; 2 - discharge zone; 3 - solution under treatment. 
with the use of synthetic porphyrins as reagents for of $\mathrm{Cu}^{2+}$ and $\mathrm{Ni}^{2+}$ ions.

Last years synthetic porphyrins are widely adopted for analytic chemistry methods as unique reagents for the detection of metal cations [14-16]. Indicator reactions of porphyrins with transition metal salts are the base of kinetic method for investigations of structures and properties of salt solvate complexes [17]. Porphyrins form stable coordination compounds with majority of metals (except alkali ones) with formula 1:1 (one ligand per one metal ion). It is important, that porphyrins and their metallocomplexes have typical electronic spectra and ultimate high absorbance factors $(\varepsilon)$, they are up to 200,000 in the range of $390-420 \mathrm{~nm}$ called Soret band [18]. But reactions of metal complex formation are prolonged enough, some orders slower than reactions with another ligands, and there are some difficulties in the detection of metal cations. From the other hand, these reactions may be easily controlled by usual chemical kinetic methods, by spectrophotometry ones, for example.

\section{MATERIALS AND METHODS}

5, 10, 15, 20-tetrakis(4-methylpyridil)porphyrin in the tetratozilat form $\left(\mathrm{H}_{2} \mathrm{TPy}\right)$ was synthesized at boiling heating 10,15, 20-tetrakis(4-pyridil)porphyrin with methyl ether $n$-toluenesulphonic acid in nitromethane.

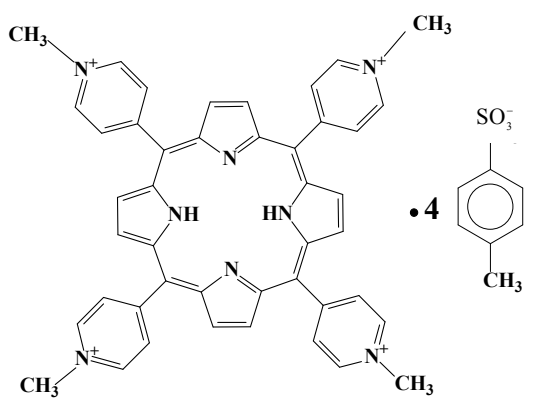

Following bands were found in absorbance electronic spectrum of $\mathrm{H}_{2}$ TPyP with $\left.\lambda_{\max }, \mathrm{nm}(\varepsilon 1 / \mathrm{mol} \cdot \mathrm{cm})\right): 420$ $\left(2.3 \times 10^{4}\right), 518\left(1.8 \times 10^{3}\right), 554,584\left(5.4 \times 10^{2}\right), 641$.

Absorbance electronic spectra (UV-VIS) were obtained by spectrophotometer "Shimadzu UV-180" (Japan). NMR were obtained by spectrometer AVANCE-500, Bruker, Germany. The IR spectra samples in $\mathrm{KBr}$ tablets were recorded on a FT-IR spectrophotometer Avatar 360 FT-IR ESP ("Thermo Nicolet", USA) in the frequency range of $400-4000 \mathrm{~cm}^{-1}$ at room temperature.

The structure of synthesized $\mathrm{H}_{2} \mathrm{TPyP}$ was confirmed by UV-VIS, IR and NMR investigations in deuterated water $[19,20]$. The study of $\mathrm{H}_{2}$ TPyP complex formation with copper salts in water solutions was carried out by methods of spectrophotometry in temperature-controlled cells in the range of $278.15-298.15 \mathrm{~K}$. Temperature fluctuations were not more than $\pm 0.02 \mathrm{~K}$. The application of this method is possible due to considerable differences in absorbance spectra of porphyrins and their metallocomplexes. Temperature-controlled solutions of porphyrin and copper nitrate (with 10 - 100 excess) were mixed in the cell, absorbance being measured in fixed time intervals at wave lengths with most optical density alterations.

Gas discharge treatment was organized as follows. The cell of glass had the volume of $100 \mathrm{ml}$. Anode in gas phase and cathode in the solution (Figure 1) were of copper (or nickel) wire with the diameter $2 \mathrm{~mm}$. Distilled water was used as electrolyte. Discharge current was 10 $\mathrm{mA}$, interelectrode gap $-2 \mathrm{~mm}$, discharge treatment time $-0.25-4$ hours. There is $\mathrm{pH}$ decreasing take place in liquid phase under glow discharge action, so after its completion solutions were neutralized by $\mathrm{NaOH}$ up to $\mathrm{pH} 6 . \mathrm{pH}$ values in the interval $3-8$ were controlled by portable $\mathrm{pH}$-meter $\mathrm{pH}-009(1)$.

\section{RESULTS AND DISCUSSION}

The application of porphyrins as high sensitive agents for metal cations detection is limited by insolubility of most porphyrins and their metallocomplexes in water. This problem may be solved in part by the use of amphiphilic porphyrins. The presence of polar groups in these compounds allows to increase their solubility in aqueous media, and high solvation index of transition state brings in whole to the acceleration of the reaction of complex formation with metal salts [21].

To estimate $\mathrm{Cu}(\mathrm{II})$ and $\mathrm{Ni}(\mathrm{II})$ concentrations in aqueous solutions after glow discharge action $\mathrm{H}_{2} \mathrm{TPyP}$ was used in the form of tetratozilat.

The disposition of these compounds towards association is important factor of influence on the reactivity of water soluble porphyrins. In weak acid and alkali aqueous solutions porphyrins of cation type may exist as equilibrium mixture of monomer and associated forms [22].

The study of $\mathrm{H}_{2} \mathrm{TPyP}$ electronic spectra in the range of concentrations $5 \times 10^{-7}-2 \times 10^{-4} \mathrm{~mol} / 1$ in aqueous and in aqueous-buffer solutions at $\mathrm{pH}=3.5-8.0$ showed the absence of location shifts of absorbance bands. Alternations of band intensities at solution dilution are in the conformance with Lambert law, values of molar absorbance factors being by this correspondingly constant. Typical examples of spectra changes at the dilution of aqueous $\mathrm{H}_{2} \mathrm{TPyP}$ solutions are presented in (Figure 2).

Data presented is the evidence of monomer form of $\mathrm{H}_{2}$ TPyP existing in aqueous solutions.

To determine the concentration of metal ions passed from electrode into electrolyte solution we studied the rate of the reaction of $\mathrm{H}_{2} \mathrm{TPyP}$ coordination by copper 


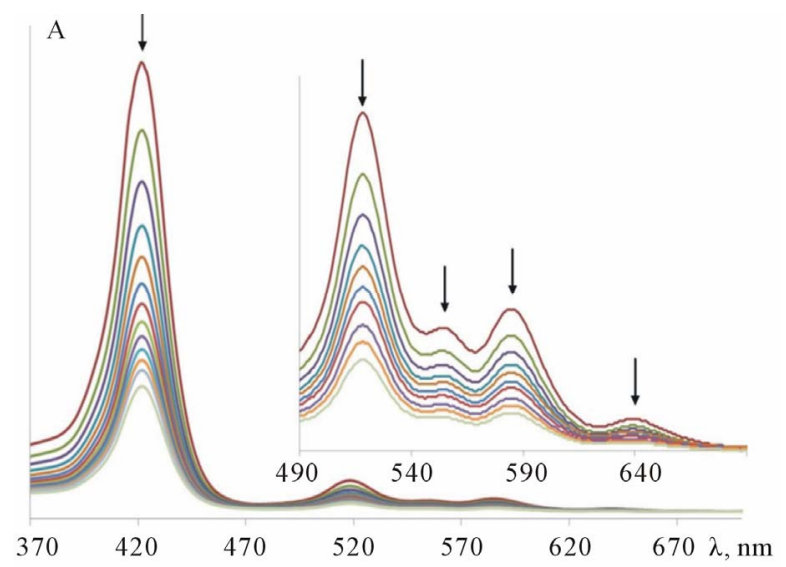

Figure 2. UV-VIS spectra of $\mathrm{H}_{2} \mathrm{TPyP}$ in water solution at diluting.

nitrate in aqueous solutions (1) at $\mathrm{pH}=6.0$. The process of metalloporphyrin formation is submitted to kinetic Eq.2, distinct isosbestic points being observed in spectra of systems under reactions (Figure 3).

$$
\begin{gathered}
\mathrm{H}_{2} \mathrm{TPyP}+\mathrm{Cu}\left(\mathrm{NO}_{3}\right)_{2} \rightarrow \mathrm{CuTPyP}+2 \mathrm{HNO}_{3} \\
\mathrm{~d}\left[\mathrm{H}_{2} \mathrm{TPyP}\right] / \mathrm{d} t=-k \cdot\left[\mathrm{H}_{2} \mathrm{TPyP}\right] \cdot\left[\mathrm{Cu}\left(\mathrm{NO}_{3}\right)_{2}\right]^{\mathrm{n}}
\end{gathered}
$$

where CuTPyP — copper porphyrin complex, $k$-reaction rate constant.

The process of copper complex formation is of the first order re ligand. It is confirmed by the linearity of $\lg \left(c_{\text {H2TPyP }}^{0} / c_{\text {H2TPyP }}\right)-t$ diagrams $\left(c_{\text {H2TPyP }}^{0}-\right.$ initial, $c_{\mathrm{H} 2 \mathrm{TPyP}}$ - porphyrin concentration in $t$ time point). Kinetic experiments were carried out at hundred fold excess of $\mathrm{Cu}\left(\mathrm{NO}_{3}\right)_{2}$ with respect to porphyrin, and it allowed us to calculate effective rate constants $\left(k_{\ni \phi}\right)$ of the reaction Eq.1 by first order equation Eq.3:

$$
k_{e f}=(1 / t) \cdot \ln \left(c_{H 2 P}^{0} / c_{H 2 P}\right)
$$

Or by the equation Eq.4 with the glance of absorbance alterations:

$$
k_{e f}=(1 / t) \times \ln \left[\left(A_{\mathrm{o}}-A_{\infty}\right) /\left(A-A_{\infty}\right)\right]
$$

where: $t$-the time from reaction start, $A_{0}, A_{t}, A_{\infty}$ - the absorbance of solution at start time, in $t$ time point and at the finish of the reaction, respectively. The data obtained and values of activation energy of reactions of copper complex formation at constant $\mathrm{pH}$ and solution ionic strength are presented in (Table 1).

To determine kinetic order of the reaction re metal salt in aqueous solutions the dependence of CuTPyP formation rate from copper nitrate concentration (Figure 4). The diagram shows reaction order re salt to be 1 . Rate constants of second order were calculated by Eq.5.

At glow discharge ignition in time ranges of $15-120$ minutes solutions with different $\mathrm{Cu}^{2+}$ concentrations were

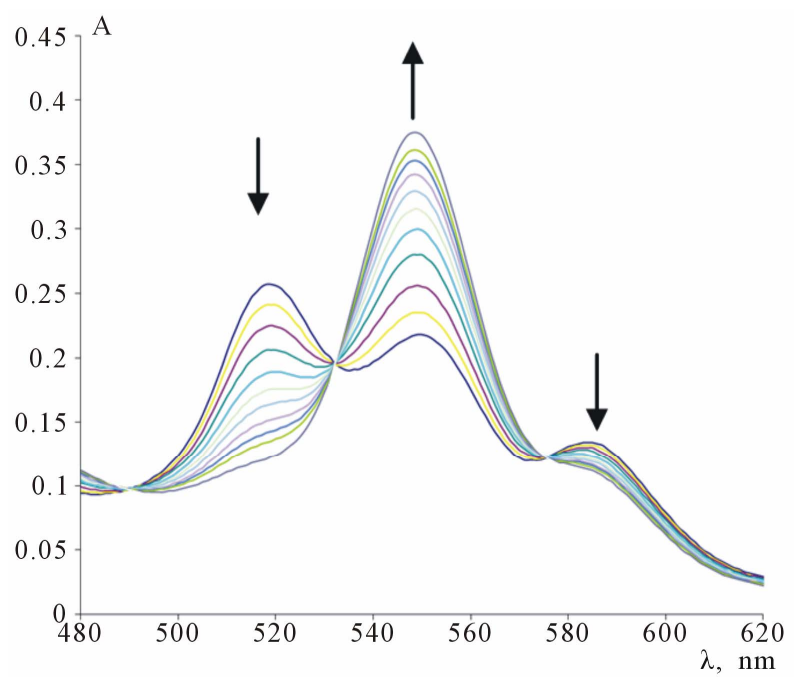

Figure 3. UV-VIS spectra of $\mathrm{H}_{2} \mathrm{TPyP}-\mathrm{Cu}\left(\mathrm{NO}_{3}\right)_{2}$ system in aqueous solution.

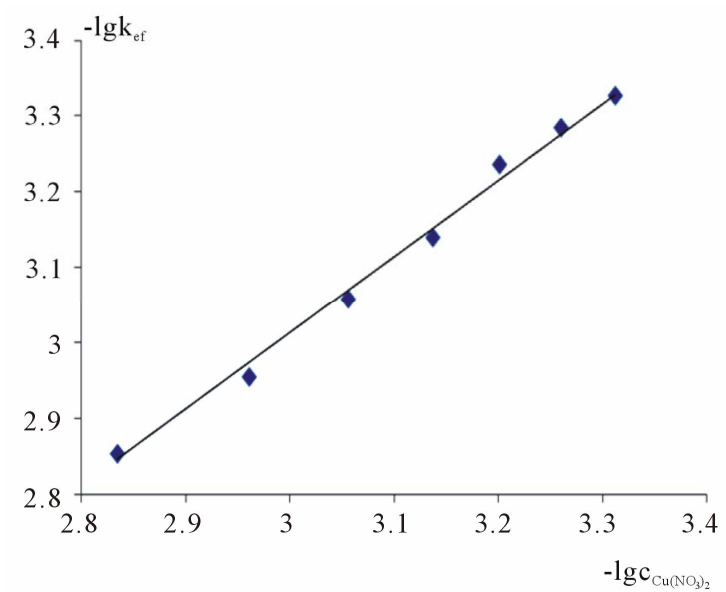

Figure 4. The dependence of $-\operatorname{lgk} \mathrm{ef}_{\mathrm{ef}}$ from $-\lg \mathrm{C}_{\mathrm{Cu}\left(\mathrm{NO}_{3}\right)_{2}}$ of $\mathrm{CuT}-$ PyP formation reaction at $298,15 \mathrm{~K}$ in water-buffer solution at $\mathrm{pH}=6$.

Table 1. Kinetic parameters of the reaction of $\mathrm{H}_{2} \mathrm{P}$ coordination by copper nitrate in water-buffer solution with $\mathrm{pH}=6(\lambda-$ analysis wavelength, $\left.c_{\mathrm{Cu}\left(\mathrm{NO}_{3}\right)_{2}}=2.5 \times 10^{-3} \mathrm{~mol} / \mathrm{l}\right)$.

\begin{tabular}{cccccc}
\hline $\begin{array}{c}k^{298} \times 10^{4}, \\
\mathrm{~s}^{-1}\end{array}$ & $\begin{array}{c}k^{289} \times 10^{4}, \\
\mathrm{~s}^{-1}\end{array}$ & $\begin{array}{c}k^{310} \times 10^{4}, \\
\mathrm{~s}^{-1}\end{array}$ & $\begin{array}{c}k_{v}^{298} \times 10^{2}, \\
1 \cdot \mathrm{mol}^{-1} \cdot \mathrm{s}^{-1}\end{array}$ & $\begin{array}{c}\Delta E, \\
\mathrm{~kJ} \cdot \mathrm{mol}^{-1}\end{array}$ & $\begin{array}{c}\lambda_{a}, \\
\mathrm{~nm}\end{array}$ \\
\hline $7.9 \pm 0.2$ & $14 \pm 0.4$ & $20 \pm 0.2$ & $32 \pm 1$ & $219 \pm 9$ & $518 ; 550$ \\
\hline$k_{2}=k_{\text {ef }} / c_{\mathrm{Cu}\left(\mathrm{NO}_{3}\right)_{2}}$ &
\end{tabular}

obtained. We had a success in the determination of copper cation concentration in the solution after $120 \mathrm{~min}$ plasma treatment only. $\mathrm{H}_{2}$ TPyP solution were added to the piece of copper containing solution, and equilibrium approach were waited for. In the case when only copper complex of porphyrin were detected portions of free ligand were added until the appearance of $\mathrm{H}_{2}$ TPyP bands 


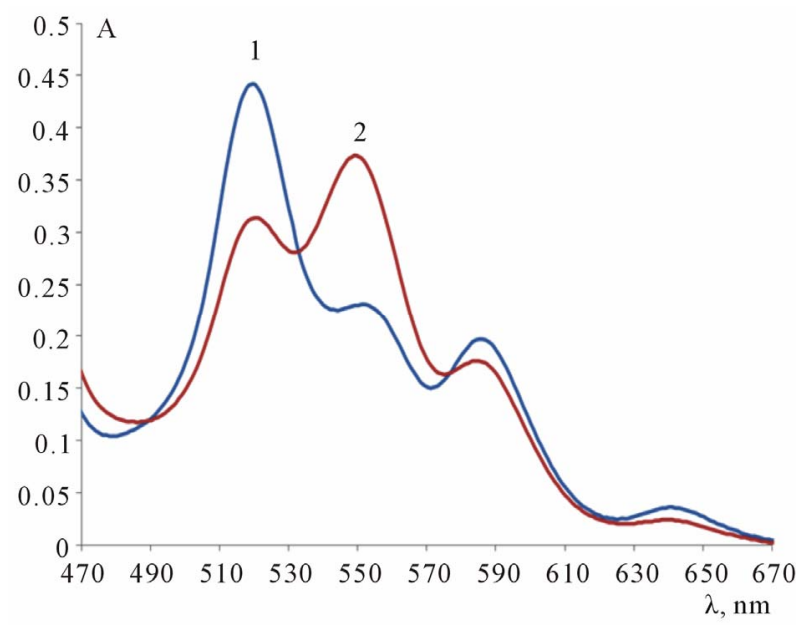

Figure 5. UV-VIS spectra of $\mathrm{H}_{2} \mathrm{TPyP}$ (1) and formation of CuTPyP (2).

in the spectrum (Figure 5). At the excess of $\mathrm{H}_{2} \mathrm{TPyP}$ the amount of the ligand off the reaction was determined. Thus, $\mathrm{Cu}^{2+}$ concentration in the solution after 120 minute discharge action was $3.24 \times 10^{-4} \mathrm{~mol} / \mathrm{l}$. The method presented has some limitations: metal concentrations lower than $\sim 10^{-6} \mathrm{~mol} / \mathrm{l}$ can't be detected. However, we can assert that at the experiment with the use of $\mathrm{Ni}$ cathode nickel cation concentration in the solution was not more than $\sim 10^{-6} \mathrm{~mol} / \mathrm{l}$ even at long discharge treatment (more than 5 hours), because there was not changes in the spectrum of $\mathrm{H}_{2}$ TPyP by the add of the solution after discharge treatment.

\section{CONCLUSION}

Possibility in principle of amphyphilic porphyrins application as sensitive reagents for the detection of metal ions passing from electrodes into electrolyte solution at gas discharge action was shown in present work. 5, 10, 15, 20-tetrakis(4-methylpyridil) porphyrin in the tetratozilat form was found to be not associated in aqueous media in wide $\mathrm{pH}$ range, hence, macroheterocycle reaction center is free for complex formation of metal ions, and this makes it sensitive to the presence of metal cation in a solution even at concentration about $10^{-6} \mathrm{~mol} / \mathrm{l}$.

\section{ACKNOWLEDGEMENTS}

The work is supported by RFBR grant No. 10-03-00305-a.

\section{REFERENCES}

[1] Moisan, M., Barbeau, J., Moreau, S., Pelletier, J., Tabrizian, M. and Yahia, L.H. (2001) Low-temperature sterilization using gas plasmas: A review of the experiments and an analysis of the inactivation mechanisms. International Journal of Pharmaceutics, 226, 1-21. doi:10.1016/S0378-5173(01)00752-9.
[2] Zakharov, A.G., Maximov, A.I. and Titova, Yu.V. (2007) Physicochemical properties of plasma-solution systems and prospects for their use in technology. Russian Chemical Review, 76, 235-251. doi:10.1070/RC2007v076n03ABEH003638.

[3] Shi, X. M., Li, Y.X., Zhang, G.J., Ma, Y. and Shao, X.J. (2011) Experimental study on inactivation of bacterial endotoxin by using dielectric barrier discharge. Plasma Science and Technology, 13, 651. doi:10.1088/1009-0630/13/6/03

[4] Titov, V.A., Rybkin, V.V., Shikova, T.G., Ageeva, T.A., Golubchikov, O.A. and Choi, H.-S. (2005) Study on the application possibilities of an atmospheric pressure glow discharge with liquid electrolyte cathode for the modification of polymer materials. Surface and Coatings Technology, 199, 231-236.

doi:10.1016/j.surfcoat.2005.01.037

[5] Malik, M.A. (2010) Water purification by plasmas: Which reactors are most energy efficient? Plasma Chemistry and Plasma Processing, 30, 21-31. doi: 10.1007/s11090-009-9202-2

[6] Joshi, R., Schulze, R.-D., Meyer-Plath, A. and Friedrich, J.F. (2008) Selective surface modification of poly(propylene) wit $\mathrm{OH}$ and $\mathrm{COOH}$ groups using liquid-plasma system. Plasma Processes and Polymers, 5, 695-707. doi: 10.1002/ppap.200700175

[7] Titov, V.A., Shikova, T.G., Rybkin, V.V., Smirnov, D.S., Ageeva, T.S. and Choi, H.-S. (2006) Modification of polyethylene, polypropylene and cotton using atmospheric pressure glow discharge with liquid electrolyte cathode. High Temperature Material Processes, 10, 467-478. doi: 10.1615/HighTempMatProc.v10.i3.100

[8] Rud, A.D., Perekos, A.E., Ogenko, V.M., Shpak, A.P., Uvarov, V.N., Chuistov, K.V., Lakhnik, A.M., Voynash, V.Z. and Ivaschuk, L.I. (2007) Different states of carbon produced by high-energy plasmochemistry synthesis. Journal of Non-Crystalline Solids, 353, 3650-3654. doi: 10.1016/j.jnoncrysol.2007.05.128

[9] Kong, M.G., Keidar, M. and Ostrikov, K. (2011) Plasmas meet nanoparticles-Where synergies can advance the frontier of medicine. Journal of Physics D: Applied Physics, 44, 174018. doi:10.1088/0022-3727/44/17/174018

[10] Lukes, P. and Locke, B.R. (2005) Plasmachemical oxidation processes in a hybrid gas-liquid electrical discharge reactor. Journal of Physics D: Applied Physics, 38, 4074 doi: $10.1088 / 0022-3727 / 38 / 22 / 010$

[11] Snizhko, L.O., Yerokhin, A.L., Pilkington, A., Gurevina, N.L., Misnyankin, D.O., Leyland, A. and Matthews, A. (2004) Anodic processes in plasma electrolytic oxidation of aluminium in alkaline solutions. Electrochimica Acta, 49, 2085-2095. doi:10.1016/j.electacta.2003.11.027

[12] Malik, M.A., Ghaffar, A. and Malik S.A. (2001) Water purification by electrical discharges. Plasma Sources Science and Technology, 10, 82. doi:10.1088/0963-0252/10/1/311

[13] Nagiev, T.M. (2006) 4-Conjugated reactions of oxidation with hydrogen peroxide in the gas phase. Coherent Synchronized Oxidation Reactions by Hydrogen Peroxide, 91145. doi:10.1016/B978-044452851-3/50005-4 
[14] Ma, D.L., Xia, D., Cui, F.L., Li, J.P. and Wang Y. (1999) A new sensitive reagent for identifying and determining $\mathrm{Cu}^{2+}$. Talanta, 48, 9-13. doi:10.1016/S0039-9140(98)00033-2

[15] Biesaga, M., Pyrzynska, K. and Trojanowicz, M. (2000) Porphyrins in analytical chemistry: A review. Talanta, 51, 209-224. doi:10.1016/S0039-9140(99)00291-X

[16] Cano-Raya, C., Fernández-Ramos, M.D. and CapitánVallvey L.F. (2006) Fluorescence resonance energy transfer disposable sensor for copper(II). Analytica Chimica Acta, 555, 299-307. doi:10.1016/i.aca.2005.09.011

[17] Berezin, B.D. (1981) Coordination compounds of porphyrins and phthalocyanines. John Wiley, Toronto.

[18] Smith, K.M. (1975) Porphyrins and metalloporphyrins. Elsevier Science, Amsterdam.

[19] Vashurin, A.S., Pukhovskaya, S.G., Semeikin, A.S. and Golubchikov, O.A. (2012) Catalytic properties of cobalt meso-tetrakis(4-methylpyridiniumyl)porphyrin tetratosy- late in the oxidation of sodium diethyldithiocarbamate. Macroheterocycles, 5, 72-75.

doi: $10.6060 / \mathrm{mhc} 2012.111251 \mathrm{v}$

[20] Ivanova, Yu.B., Mamardashvili, N.Zh., Semeikin, A.S. and Glazunov, A.V. (2010) Pyridyl-substituted porphyrins: I. synthesis and basicity of monopyridylporphyrins. Russian Journal of Organic Chemistry, 46, 144-149. doi: 10.1134/S1070428010010161

[21] Hambright, P. (2009) Chemistry of water soluble porphyrins. In: Kadish, K., Smith, K. and Guilard, R., Eds., The Porphyrin Handbook, Elsevier, Academic Press, 3, 132-208.

[22] Sutter, T.P.G., Rahimi, R., Hambraght, P., Boomer, J., Kumar, M. and Neta, P.J. (1993) Steric and inductive effects on the basicity of porphyrins and on the site of protonation of porphyrin dianions: Radiolytic reduction of porphyrins and metalloporphyrins to chlorins or phlorins. Journal of the Chemical Society, Faraday Transactions, 89, 495-502. doi:10.1039/FT9938900495 